\title{
Monoclonal Antibody MDX-22
}

National Cancer Institute

\section{Source}

National Cancer Institute. Monoclonal Antibody MDX-22. NCI Thesaurus. Code C2010.

A monoclonal antibody used to purge leukemia cells from bone marrow. $(\mathrm{NCl})$ 